\title{
LEARNING ORGANIZATIONS AND THEIR ADAPTABILITY TO MARKET ENVIRONMENT Małgorzata Okręglicka ${ }^{1}$, Anna Lemańska-Majdzik² ${ }^{2}$ Iwona Gorzeń-Mitka ${ }^{3}$
}

\author{
Faculty of Management, Czestochowa University of Technology, \\ Dabrowskiego 69, 42-201 Częstochowa, Poland \\ E-mails: ${ }^{1}$ m.okreglicka@wp.pl (corresponding author); ${ }^{2}$ lemanska@zim.pcz.pl; ${ }^{3}$ iwona.mitka@wp.pl
}

\begin{abstract}
To achieve an economic success many economic entities decided to adopt the rules and principles of learning organizations. The main aim of this article is to identify and analyze the selected aspect of the adaptability to the market environment in the group of learning enterprises in Poland. The verification of the hypothesis, presented in the paper, has been based on the results of questionnaire empirical studies conducted in 2016 on a group of 250 SMEs in Poland. The studies resulted in finding statistical dependencies that show the correlation between the level of organizational learning and adapting to changes appearing in the environment.
\end{abstract}

Keywords: learning organization, environment, adaptability, management, knowledge, SME.

JEL Classification: M10; M12; M15.

\section{Introduction}

It become visible that globalization and diversity issues are more and more crucial not only to the survival but to the successful functioning of business entities as well, when dealing in the world of rapid changes and growing competition in the marketplace. Currently, the dynamically developing market environment is typical for its elements of high complexity and uncertainty, enterprises are led to the need of use all the knowledge to increase their economic efficiency and market position. Knowledge become the most important factor determining the success and survival in long-term. However, knowledge acquiring is not a natural, cost free process. Organizations need to engage the significant amount of resources to possess information, technology or know-how.

Analyzing the recent studies, we can see that the essential role of learning and knowledge in the management of enterprises has become the important research subjects in economic science (Currah, Wrigley 2004). The explanation of this situation is that the constant learning has become a basic element for organization development, trying to adapt to the changes in the environment (Fard et al. 2009) and taking advantages of them. As the environment become more and more turbulent, there is a need of intensification of the learning process in the companies.

The process of organizational learning is a tool for present enterprises regulating their activities in an unstable environment, allowing generate knowledge from their own experience and the experiences of the others and moreover creating unique knowledge resources in particular surroundings (Ziółkowska, Tomski 2013). Organizational learning is often connected to changes associated to environment adaptation and transformation. Based on information from surrounding, learning organizations adapt their forms and methods of functioning to be more competitive (Ogrean et al. 2009). This adaptation could be, however, not enough to keep up with the rapid changes, it is necessary to discover completely new economic solutions.

Small and medium-sized enterprises play undeniably crucial role in each economy. These businesses are generally regarded as the driving force of economic growth, workplaces creation, improvement of the flexibility and competitiveness of markets, and poverty reduction in developing countries (Betakova et al. 2014; Okręglicka et al. 2015). Small and medium-sized enterprises are responsible for the proper level of competitiveness of the markets, avoiding their monopolization, and effectively improve flexibility of the supply. SME development should be than the priority of each government. The national and local authorities should improve the condition of creating and running of small business, basing on the professional analysis of the economic reality. It emphasizes the importance of the constant analyzing of this sector in order to intensify its future development. As this issue is complicated and multidimensional the analyzes of this area relate to the selected problems or areas. 
The main aim of this article is to identify and analyze the selected aspect of the adaptability to the market environment in the group of learning enterprises in Poland.

\section{Theoretical background}

The issues of learning organizations are wide and multidimensional. Levitt and March (1988) pointed, that in theories on organizational learning appeared the idea that there are dependencies between organizational learning, organizational performance and organizational intelligence. Organizations focused on learning can find and apply new economic solutions, achieving in this way the competitive advantage.

Organizations cannot operate independently in the full meaning. They are open systems and built networks with other organizations or elements of environment. Hannah and Lester (2009) underline that enterprise ability to learn and their adaptation skills allow them to survive and develop when meet threats and opportunities created by complex external environments. Consequently, existing business volatility leads the organizations to base their action on regular creation and integration of new knowledge, and thus, to adopt the model of learning organization for their daily operation if they want to achieve better organizational performance and sustainable competitiveness (Dekouloua, Trivellasb 2015). The advancement of the learning model depends on many determinants, including the characteristics of the organization, especially its size and market experience. This is why small enterprises have many problems with the implementation of a coherent model of learning, although they fully understand its economical importance.

Since the term "organizational learning" was first used a quarter of a century ago in a work by Argyris and Schon, the intensive evolution of this idea took place in economic reflections. Firms found very quickly that organizational learning and learning tools and techniques can bring many competitive benefits for them. Fulmer et al. (1998) confirmed that the further evolution of organizational learning, using the existing learning tools for new aims and the constant development of learning tools lead to achieve corporate competitive advantage on the market.

We can find many definitions and descriptions of learning organizations in literature. One of the first was this created by Senge (1990), who defines learning organizations as "organizations where people continually expand their capacity to create the results they truly desire". He stated that in a learning organization (company), new and expansive patterns of thinking are nurtured, joint aspirations are set free, and the entities are continually expanding its capacity to its future creation (Worrell 1995). In contrast to the Senge's abstract definition, Garvin (1993) formulates much more practical term in which learning organizations are skilled at creating, acquiring, and transferring knowledge, and based on new knowledge they are ready to change its own thinking, behavior and actions. Therefore, learning organizations have ability not only to possess new knowledge, but, what is more important, can use this new knowledge for improving its performance.

The present definitions develop and detail the learning organization term. For example, Kanten et al. (2015) indicate that learning organization focuses on "learning" as a crucial component in its visions, goals, values and all of its functions. Therefore, learning organization basically refers to a culture that promotes learning environment, which includes both individual and organizational learning. Watkins and Marsick (2003) state that entity becomes a learning organization when it learns continuously and transforms itself. I turn, Juceviciene and Leonaviciene (2007) emphasize that the learning organizations, by breaking their boundaries created by the past experiences during learning process, are looking for the solutions, which could be more effective and efficient for the economic entity. They can leave the existing paths and habits, believing that only constant improvements allow surviving in the changeable environment.

In other approach, a structure of learning organization is shaped in a specific form, which is focused on constant self-improvements by making it easier for the staff to learn (Yaşlıoğlu et al. 2014). Alipour et al. (2011) stresses that all members of learning organization have facilitated access to learning, by which it consciously reform itself and affects its context in order to improve existing systems to acquire and share knowledge so that the progression continuation and further competitive development can be ensured (Calantone et al. 2002).

According to Watkins and Marsick (2003), there are seven dimensions essential for a learning organization (Fig. 1).

Watkins and Marsick (2003) pointed that the above elements integrated in a single approach be the key determinants of organizational learning,leading enterprises toward becoming "typical" learning organizations, with all its characteristics. 


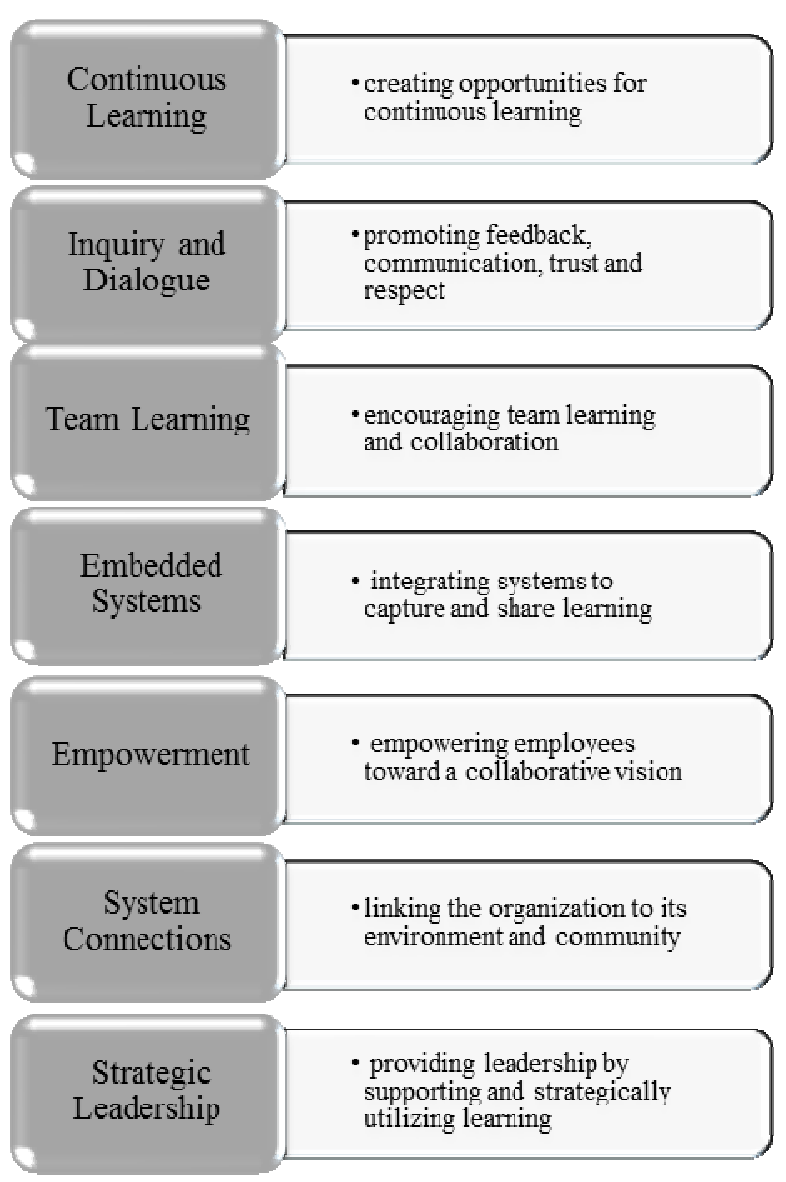

Fig. 1. Dimensions essential for a learning organization (Source: Watkins, Marsick 2003)

Creating this type of organization require the engagement not only assets and financial resources, but also the radical change in human resource management, creating new way of thinking and cooperating.

In this area, it is stated that individual person is always the start and end of all learning processes. People (not organizations) are responsible for new knowledge creation or acquisition form the others, knowledge dissemination, and its implementation in organizational processes and systems. Smith et al. (2014) argues that members of the learning organization should not only accept orders from superiors, so be the passive recipient of orders. They need to be encouraged to question established norms to explore new avenues of thinking and to make mistakes in order to improve their products/services and production methods. However, it needs to create the completely new model of relations between subordinates and superiors. It seems to be particularly difficult in small and medium-sized enterprises, there the whole management is focused in the person of the owner, who often uses authoritarian management system, which does not take into consideration the collec- tive decision-making. It is concluded that the idea of learning organization is based on the belief that by collective learning, the organization's members are able to improve the organizations performance and competitive advantages. Additionally, it is pointed that the individual learning process has usually voluntary rather than compulsory character, and the biggest challenge is increasing the willingness to learn and than share new knowledge. However, just sharing knowledge could be not enough because people need to reflect this knowledge through their actions and behaviors to enhance organizational learning.

In literature, there is a difference between two very close but still separated ideas: the learning organization and organizational learning. The construct of the learning organization normally describes such entities, which possess the skills of permanent learning and adaptive characteristics, but also developed them in the continuous way. In turn, organizational learning, in general, be a sign of joint learning experiences used to acquire knowledge and develop skills (Lemańska-Majdzik 2014). This distinction is significant because it shows all learning organizations feature learning at all levels: individual, group and organizational. However, if there are some elements of organizational learning in company, used at the organizational level, it doesn't automatically means that we deal with learning organization, which is much wider term. It needs to be organized in the form of coherent system or (in smaller entities) to become a habit, not only incidental activity, which is a result of the current need. Moreover, the learning in organization should be a part of the general strategy of the company, included in all firm's shortand long-term plans.

Learning organization is identified as one of the firm strategy to improve its performance. The positive correlation between learning ability of organization and its financial performance was studied by many researches (Som et al. 2015).

According to findings in various researches, organizational learning provides competitive advantage for companies through fostering innovations (Sipa, Skibiński 2015). They launch innovative and rather competitive products or services, introduce innovatory working practices and standards, and ensure constant staff learning improvement and new, advanced technology absorption (Garrido, Camarero 2010).

Many studies present that learning organizations can successfully adapt to the changing environment conditions. According to Senge (1990), in the more interconnected world and by the com- 
plexity and dynamics existing in business environment, all the economic activities must become more "learningful". Nzuve and Omolo (2012) indicate the most spectacular transitions in corporate environment, including:

- Increased competition.

- Rapid advancements in ICTs.

- More informed and demanding global population.

- Increasingly complex (and not so stable as expected) global financial system.

- Last economic recession etc.

The above changes become more and more critical for functioning of organization. We can say that the change is nowadays a normal situation and cannot look forward to the balance.

Many organizations do not succeed in learning because their management boards have a stiff vision of their functioning, which is considerably separated apart from their environment (GarcíaMorales et al. 2006). Firms preferring the learning organization model in their actions, effectively find and take advantage of opportunities and avoid threats, and therefore effectively utilize their resources in order to meet market demands and trends (Yeung et al. 2006). In other words, the more an enterprise is capable of at creating, acquiring, and transferring knowledge and change themselves basing on the possessed information's (Garvin 1993), the more likely it is able to deal in a rapidly changing, dynamic surrounding of corporate sector.

Studying learning organizations can bring new insights for makers of strategy, since learning organization is able to meet and shape the demands of its markets (Kuşcua et al. 2015). Learning capability can foster enterprises, especially small and medium-sized, an ability to identify and respond to market requirements better cheaper or faster than market rivals (Sok et al. 2013). It shortens delivery time of goods to marketplace and increases the pace of solving the unexpected problems or complaints reported by clients (Kumar 2005). Learning capability enables enterprises to identify channels and networks to work more directly with their customers, and in this way to differentiate themselves from their rivals (Sok, O'Cass 2011). Learningoriented operations facilitate interaction between parties of transactions: customers and staff, and provide the enterprise with proper and extended information about client tastes, needs and selection criteria (Chenhall 2005). They increase satisfaction and loyalty of the customers reinforcing enterprise's brand name and image.

\section{Research description and methodology}

The issues of learning in organization and its influence on functioning in many its areas is very wide, so the holistic view on this issue is very difficult. This is why the researches focused mostly on the selected parts of this phenomenon.

The main aim of this article is to identify and analyze the selected aspect of the adaptability to the market environment in the group of learning enterprises in Poland.

The study starts with a literature review in order to highlight the importance of learning process in the organization. Research papers considered for inclusion in this literature review are written mostly in English, from peer-reviewed journals or monographs, and accessible through electronic management databases. Then authors will go on to development of the hypothesis:

H1 - Enterprises with stronger focus on learning adapt to market environment better than those with moderate focus on learning.

In order to confirm/reject the hypothesis the author conducted a questionnaire survey in 250 enterprises from the small and medium-sized enterprises sector from the south of Poland. The research group selection had an accidental character, and this is why study should be treated as a seed research, identifying correlations/trends, which should be confirmed, based on representative sample.

During the elaboration of the paper, the generally accepted methods of economic research were used, including statistical analysis (Gamma correlation coefficient) and graphical illustration methods.

The research process was performed in several consistent stages:

- Preparing the survey questionnaire and realizing the survey.

- Preliminary evaluation of research material.

- Selection the group of enterprises, which could be described as learning organization $(39.2 \%)$ from the total population.

- Data analyzing for the selected group and preparing presentation of the research result.

The research group selection was based on the combination of approaches presented in literature. The survey was directed to enterprises of different size, so it was decided that the definition should be simplified to be understandable for any entrepreneur, even without management knowledge. The selection of the research group is therefore the 
opinion of entrepreneurs about their companies (in 4-point scale), created as an answer to the question: Could you evaluate your company as a learning organization i.e., open to the acquisition of knowledge, focused on the continuous development and flexibly transforming itself to adapt to the changing environment.

The presented results base on the opinions of managers or owners of the enterprises. The 4-range scale was adopted: from 1 - definitely not to $4-$ definitely yes.

\section{Research results and discussion}

The issue of the learning organizations and its correlation with the environment is complex and multi-threaded. For the purpose of this paper several aspects were chosen, which are divided into two groups.

First group of questions concerns the intensity of obtaining information from the environment, which can be used to introducing changes in the functioning and using alternative management tools/methods. The new knowledge can appear in the company only through the process of acquiring (and proper use) of information, both internal and external.

We assumed that in learning organization the process of acquisition of information should be intense, multilateral, but also systematic and organized.

Therefore, this group consists of four questions assessed by managers or owners of enterprises:

A. Employees have wide access to information even beyond their current operating needs.

B. There is a systematic collection of information in the company about the environment (competitors, purchasers, economic and technological trends).

C. The collected information is analyzed and based on them needed changes in functioning are introduced.

D. The company compares the achieved results with the environment (competitors, industry).

Analyzing the distribution of answers (Fig. 2) we can generally stated that the mean mostly under 3 in 4-point scale is not a satisfactory result, considering the learning organizations, which are the subject of the research, should be extremely sensitive on changes in the environment and thus constantly focused on the acquisition of new information. Only the question considering a systematic collection of information in the company about the environment achieved the slightly better result above

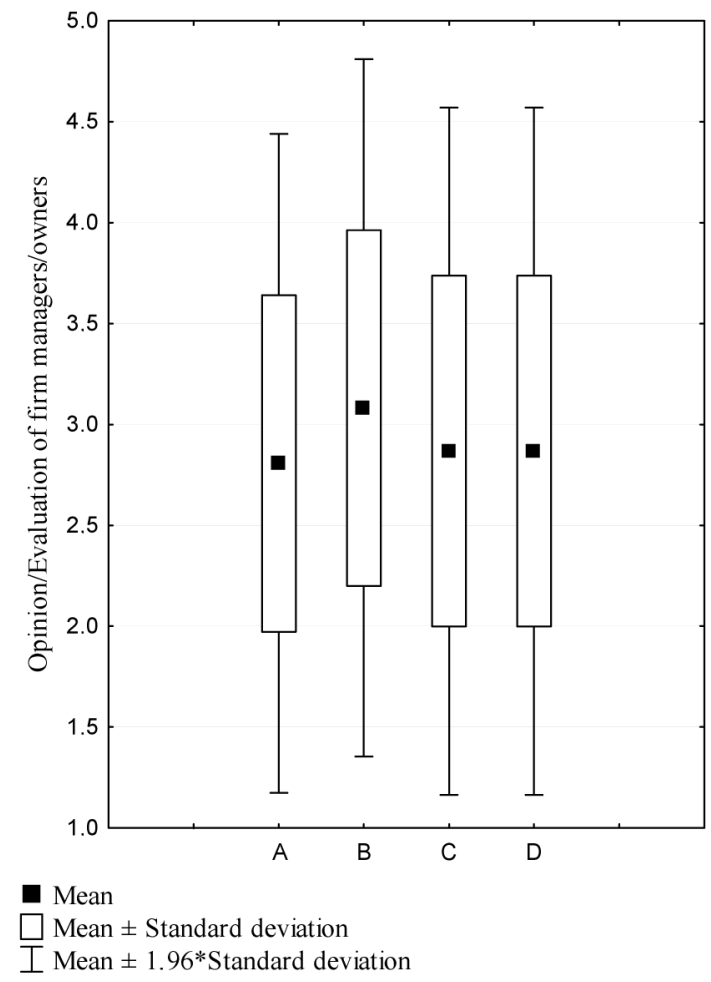

Fig. 2. Distribution of answers - group 1 (Source: authors)

The next step of the research was a diagnosis if there is any correlation between attitude to learning of the organization and approach to accumulation and using of information from the environment. To this analysis the gamma correlation coefficient was chosen as the most suitable for the collected data (the learning of enterprises was assessed in 2-point scale as moderate level of learning and strong level of learning).

There are visible positive dependencies in all analyzed questions and additionally in the case of question $\mathrm{B}$ and $\mathrm{C}$ the dependencies could be described as strong (Table 1). It means that the more the organization is focused on learning the more it is involved in collecting, processing and using of

Table 1. Gamma correlation between selected questions - group 1 and level of learning in organization (Source: authors)

\begin{tabular}{c|c}
\hline Question & Level of learning of the company \\
\hline A & $0.329^{*}$ \\
\hline B & $0.753^{*}$ \\
\hline C & $0.693^{*}$ \\
\hline D & $0.428^{*}$ \\
\hline
\end{tabular}

Note: ${ }^{*} \mathrm{p}$-value $=0.05$. 
external information. It confirm the general statement visible in literature, that information is crucial for performance improving an learning organizations are focused on information capturing from the surroundings.

The second group of questions relate in particular to adaptation to changing conditions in organization's environment. Three questions were chosen to this group:

E. On an ongoing basis company analyzes and modifies plans of its development.

F. Changes in the functioning of the company are systematically planned and introduced.

G. The company adapt to market changes quickly and flexibly (in the opinion of managers/owners).

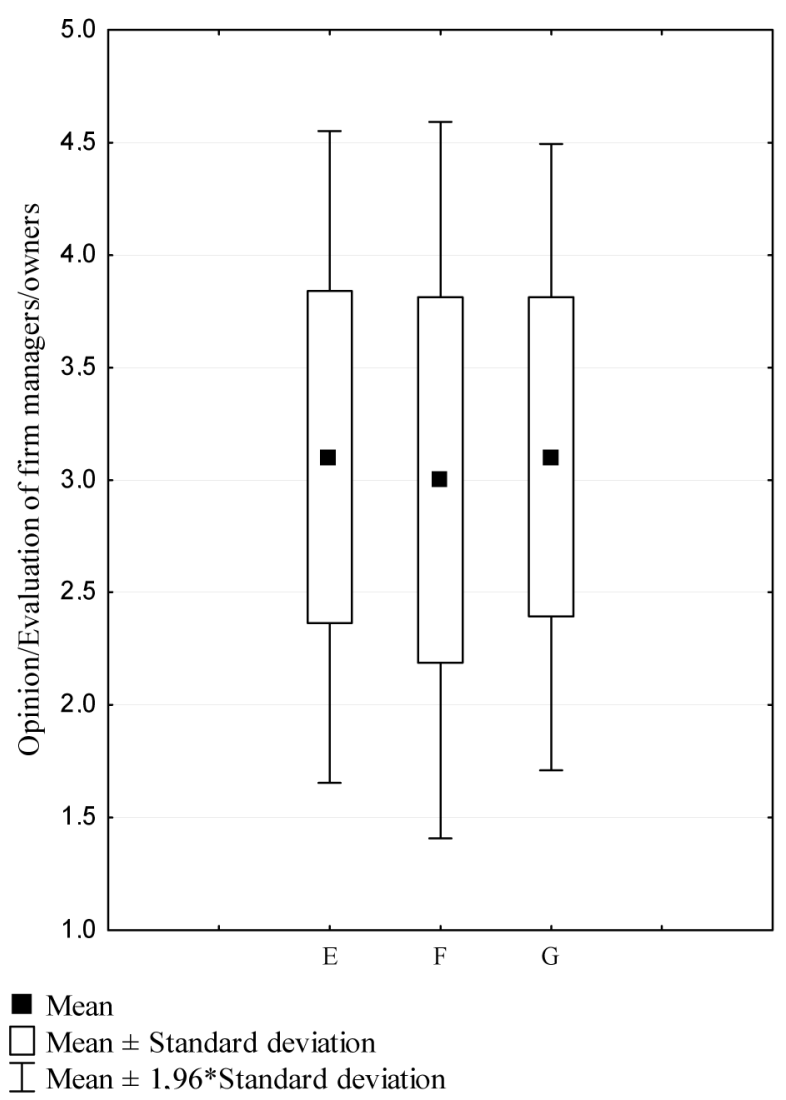

Fig. 3. Distribution of answers - group 2 (Source: authors)

In opinions of managers/owners, Polish enterprises actively adapt to the changes in environment, both competitive and macro environment (Fig. 3).

The mean for all the answers presented in Figure 3 is above 3 in 4-point scale. It could be assessed as positive situation, emphasizing the role of organizational learning in adaptability to changes and strengthening of the firm's competitive position.
The further analysis confirmed the strong positive relations between attitude to learning of the organization and the adaptive skills to the changes in the environment (Gamma coefficient $>0.5$ ). It means that the growth of the adaptability is closely connected with the increasing level of learning of the organizations, especially in the sector of small and medium-sized enterprises, which were analyzed (Table 2).

Positive and mostly strong correlation in all studied areas indicates that these relations are rather constant. It creates the proper core for future representative research.

Table 2. Gamma correlation between selected questions - group 2 and level of learning in organization (Source: authors)

\begin{tabular}{c|c}
\hline Question & Level of learning of the company \\
\hline $\mathrm{E}$ & $0.505^{*}$ \\
\hline $\mathrm{F}$ & $0.588^{*}$ \\
\hline $\mathrm{G}$ & $0.631^{*}$ \\
\hline
\end{tabular}

Note: ${ }^{*} \mathrm{p}$-value $=0.05$.

In the research process the authors try to find other correlation with features describing enterprises. Among eight characteristics, the analyzed questions stay in correlation only with the scope of activity (local, regional and national). The questions $\mathrm{A}, \mathrm{B}, \mathrm{C}, \mathrm{D}, \mathrm{E}$ show the visible dependencies with statistical significance $(p=0.05)$. We cannot confirm the correlation regarding to questions $\mathrm{F}$ and $\mathrm{G}$ (Table 3).

Table 3. Gamma correlation between selected questions and the geographical scope of activity in learning companies (Source: authors)

\begin{tabular}{c|c}
\hline Question & Level of learning of the company \\
\hline A & $0.310^{*}$ \\
\hline B & $0.333^{*}$ \\
\hline C & $0.286^{*}$ \\
\hline D & $0.263^{*}$ \\
\hline E & $0.253^{*}$ \\
\hline F & 0.139 \\
\hline G & 0.162 \\
\hline
\end{tabular}

Note: ${ }^{*} \mathrm{p}$-value $=0.05$.

Additionally, we expected initially the correlation of the analyzed areas with the size of enterprises or their age (period of functioning on the market), but after the detailed statistical analysis our expectation cannot be confirmed. 


\section{Conclusions and limitations}

Current economic activity is characterized by the forces of globalization, technology, deregulation and democratization jointly creating an extremely complex operating environment for companies (Gorzeń-Mitka, Okręglicka 2014). Learning is essential for organizations to efficiently adapt to these complex environmental conditions and generate long-term value over competitors (Kandemir, Hult 2005; Fraj et al. 2015). Organizational learning is especially important for small and mediumsized enterprises influencing their development and indirectly the development of the whole economy.

This paper examined the links between focus on learning of the enterprises from the small and medium-sized enterprise sector in Poland and their ability to adaptation to the turbulent market environment. After statistical analysis of the data obtained during questionnaire research process, many statistically significant correlations were found, confirming the research hypothesis that enterprises with stronger focus on learning adapt to market environment better than those with moderate focus on organizational learning.

The results of this study confirm that learning organizations respond to changes actively by collecting, processing and using external information. They are open for the inflow of the new data, and are willing to process and use of them. Learning enterprises make efforts to acquired knowledge, which becomes a significant source of competitive advantage.

This paper is not free of limitations. The strongest limitation of present research is the unrepresentative research group, so the challenge for the future is to create and realize the fully representative research in the area of process management and process maturity in Polish SMEs. The second problem was the using the proper definition of learning organizations. It is not a unified concept and the literature review showed that the definitions are presented in different way. Additionally, the research group consisted from small and medium-enterprises, which necessitates the using of the simplified description of learning organization.

\section{References}

Alipour, F.; Idris, K.; Karimi, R. 2011. Knowledge creation and transfer: role of learning organization, International Journal of Business Administration 2(3): 61-67. http://dx.doi.org/10.5430/ijba.v2n3p61
Betakova, J.; Dvorsky, J.; Haviernikova, K. 2014. Social capital and safety perception as aspect of improving regional competitiveness of territory, in $2^{\text {nd }}$ International Conference on Management Innovation and Business Innovation (ICMIBI 2014), 8-9 December 2014, Bangkok, Thailand.

Calantone, R.; Cavusgil, S.; Zhao, Y. 2002. Learning orientation, firm innovation capability, and firm performance, Industrial Marketing Management 31(6): 515-524.

Chenhall, R. H. 2005. Integrative strategic performance measurement systems, strategic alignment of manufacturing, learning and strategic outcomes: an exploratory study, Accounting, Organizations and Society 30: 395-422. http://dx.doi.org/10.1016/j.aos.2004.08.001

Currah, A.; Wrigley, N. 2004. Networks of organizational learning and adaptation in retail TNCs, Global Networks 4(1): 1-23.

Dekouloua, P.; Trivellasb, P. 2015. Measuring the impact of learning organization on job satisfaction and individual performance in Greek advertising sector, Procedia - Social and Behavioral Sciences 175: 367-375. http://dx.doi.org/10.1016/j.sbspro.2015.01.1212

Fard, H. D.; Rostamy, A. A.; Taghiloo, H. 2009. How types of organizational cultures contribute in shaping learning organizations, Singapore Management Review 31(1): 49-61.

Fraj, E.; Matute, J.; Melero, I. 2015. Environmental strategies and organizational competitiveness in the hotel industry: the role of learning and innovation as determinants of environmental success, Tourism Management 46: 30-42. http://dx.doi.org/10.1016/j.tourman.2014.05.009

Fulmer, R. M.; Gibbs, P.; Keys, J. B. 1998. The second generation learning organizations: new tools for sustaining competitive advantage, Organizational Dynamics 27(2): 7-20. http://dx.doi.org/10.1016/S0090-2616(98)90020-1

García-Morales, V. J.; Llorens-Montes, F. J.; VerdúJover, A. J. 2006. Antecedents and consequences of organizational innovation and organizational learning in entrepreneurship, Industrial Management \& Data Systems 106(1): 21-42. http://dx.doi.org/10.1108/02635570610642940

Garrido, M. J.; Camarero, C. 2010. Assessing the impact of organizational learning and innovation on performance in cultural organizations, International Journal of Nonprofit and Voluntary Sector Marketing 15: 215-232.

http://dx.doi.org/10.1002/nvsm.384

Garvin, D. 1993. Building a learning organization, Harvard Business Review 71(4): 78-91.

Gorzeń-Mitka, I.; Okręglicka, M. 2014. Managing complexity: a discussion of current strategies and approaches, Procedia Economics and Finance 27: 438-444.

http://dx.doi.org/10.1016/S2212-5671(15)01018-7 
Hannah, S. T.; Lester, P. B. 2009. A multilevel approach to building and leading learning organizations, The Leadership Quarterly 20: 34-48. http://dx.doi.org/10.1016/j.leaqua.2008.11.003

Juceviciene, P.; Leonaviciene, R. 2007. The change of human resource development concepts in the process of becoming a learning organisation, Economics and Management 12: 569-575.

Kandemir, D.; Hult, G. 2005. A conceptualization of an organizational learning culture in international joint ventures, Industrial Marketing Management 34(5): 430-439. http://dx.doi.org/10.1016/j.leaqua.2008.11.003

Kanten, P.; Kanten, S.; Gurlekc, M. 2015. The effects of organizational structures and learning organization on job embeddedness and individual adaptive performance, Procedia Economics and Finance 23: 1358-1366. http://dx.doi.org/10.1016/S2212-5671(15)00523-7

Kumar, N. 2005. Assessing the learning culture and performance of educational institutions, Performance Improvement 44(9): 27-32. http://dx.doi.org/10.1002/pfi.4140440906

Kuşcua, Z. K.; Yenerb, M.; Gürbüz, F. G. 2015. Learning organization and its cultural manifestations: evidence from a global white goods manufacturer, Procedia - Social and Behavioral Sciences 210: 154-163. http://dx.doi.org/10.1016/j.sbspro.2015.11.354

Lemańska-Majdzik, A. 2014. Role of knowledge in managing an enterprise, in S. Hittmar (Ed.). Theory of Management 7. The selected problems for the development support of management knowledge base. Scientific Papers. Zilina: EDI-University of Zilina.

Levitt, B.; March, J. G. 1988. Organizational learning, Annual Review on Sociology 14: 319-340. http://dx.doi.org/10.1146/annurev.so.14.080188.00 1535

Nzuve, S. N. M.; Omolo, E. A. 2012. A study of the practice of the learning organization and its relationship to performance among Kenyan commercial banks, Problems of Management in the $21^{\text {st }}$ Century 4: 45-56.

Ogrean, C.; Herciu, M.; Belascu, L. 2009. Searching for sustainable competitive advantage - from tangibles to intangibles, Journal of US-China Public Administration 6(4): 1-9.

Okręglicka, M.; Mynarzová, M.; Kaňa, R. 2015. Business process maturity in small and medium sized enterprises, Polish Journal of Management Studies 12(1): 121-131.

Senge, P. M. 1990. The fifth discipline, the art and practice of the learning organization. New York: Doubleday/Currency.

http://dx.doi.org/10.1002/pfi.4170300510
Sipa, M.; Skibiński, A. 2015. Innovative strategies of small enterprises in Poland, in 12th International Conference Liberec Economic Forum, 16-17 September 2015, Liberec, Czech Republic.

Smith, G. E.; Barnes, K. J.; Harris, C. 2014. A learning approach to the ethical organization, Learning Organization 21(2): 113-125. http://dx.doi.org/10.1108/TLO-07-2011-0043

Sok, P.; O'Cass, A. 2011. Achieving superior innovation-based performance outcomes in SMEs through innovation resource-capability complementarity, Industrial Marketing Management 40: 1285-1293. http://dx.doi.org/10.1016/j.indmarman.2011.10.007

Sok, P.; O’Cass, A.; Sok, K. M. 2013. Achieving superior SME performance: Overarching role of marketing, innovation, and learning capabilities, Australasian Marketing Journal 21: 161-167. http://dx.doi.org/10.1016/j.ausmj.2013.04.001

Som, H. B. M.; Nam, R. Y. T.; Wahab, S. A.; Nordin, R.; Mashkuri, A. H. 2015. The implementation of learning organiation elements and their impact towards organiational performance amongst NPOs in Singapore, International Journal of Business and Management 7(12): 2-23.

Watkins, K. E.; Marsick, V. J. 2003. Making learning count! Diagnosing the learning culture in organizations. Thousand Oaks, CA: Sage.

Worrell, D. 1995. The learning organization: management theory for the information age or new age fad?, The Journal of Academic Librarianship 21(5): 351-357.

Yaşlığlu, M. M.; Şap, Ö.; Toplu, D. 2014. An investigation of the characteristics of learning organizations in Turkish companies: scale validation, Procedia - Social and Behavioral Sciences 150: 726734. http://dx.doi.org/10.1016/j.sbspro.2014.09.037

Yeung, A. C. L.; Lai, K. H.; Yee, R. W. Y. 2006. Organizational learning, innovativeness, and organizational performance: a qualitative investigation, International Journal of Production Research 45(11): 2459-2477. http://dx.doi.org/10.1080/00207540601020460

Ziółkowska, B.; Tomski, P. 2013. Identyfikacja efektów międzyorganizacyjnego uczenia się w zarządzaniu przedsiębiorstwem $\mathrm{w}$ otoczeniu sieciowym [Identification of the effects of the inter-organizational learning in business management in a network environment], Prace Naukowe Uniwersytetu Ekonomicznego we Wroctawiu 310: 151-163 (in Polish). 